\title{
EARLINET: 12-YEAR OF AEROSOL PROFILING OVER EUROPE
}

L. Mona ${ }^{1}$, L. Alados Arboledas' ${ }^{2}$, V. Amiridis ${ }^{3}$, A. Amodeo' ${ }^{1}$, A. Apituley ${ }^{4}$, D. Balis ${ }^{5}$, A. Comeron ${ }^{6}$, M. Iarlori ${ }^{7}$, H. Linné ${ }^{8}$, D. Nicolae ${ }^{9}$, A. Papayannis ${ }^{10}$, M.R. Perrone ${ }^{11}$, V. Rizi ${ }^{7}$, N. Siomos ${ }^{5}$, U. Wandinger $^{12}, X$. Wang ${ }^{13}$ and G. Pappalardo ${ }^{1}$

${ }^{1}$ Istituto di Metodologie per l'Analisi Ambientale CNR-IMAA, C.da S. Loja, I-85050 Tito Scalo, Potenza, Italy, *Email: lucia.mona@imaa.cnr.it

${ }^{2}$ Andalusian Institute for Earth System Research. IISTA-CEAMA, Universidad de Granada, Spain

${ }^{3}$ National Observatory of Athens, IAASARS, Athens, Greece

${ }^{4}$ KNMI - Royal Netherlands Meteorological Institute, The Bilt, The Netherlands

${ }^{5}$ Aristotle University of Thessaloniki, 54124 Thessaloniki, Greece

${ }^{6}$ Universitat Politècnica de Catalunya, Barcelona, Spain

${ }^{7}$ CETEMPS/Dipartimento di Scienze Fisiche e Chimiche - Università Degli Studi dell'Aquila, Italy

${ }^{8}$ Max-Planck-Institut für Meteorologie, Hamburg, Germany

${ }^{9}$ National Institute of R\&D for Optoelectronics, Magurele-Bucharest, Romania

${ }^{10}$ National Technical University of Athens, Physics Department, Athens, Greece

${ }^{11}$ Università del Salento, Department of Mathematics and Physics, Lecce, Italy

${ }^{12}$ Leibniz-Institut für Troposphärenforschung, Leipzig, Germany

${ }^{13}$ Consorzio Nazionale Interuniversitario per le Scienze Fisiche della Materia, Napoli, Italy

\begin{abstract}
EARLINET has been collecting high quality aerosol optical profiles over Europe since 2000. The comparison with automatic collected dataset of aerosol optical depth (AOD) from AERONET and MODIS demonstrates the effectiveness of EARLINET regular measurement schedule for climatological studies. The analysis of optical properties in the local boundary layer indicates that the general decrease of AOD observed by different platforms over Europe in the last decade could be due to the modification of aerosol properties (towards less absorbing and larger particles) in the lower troposphere.
\end{abstract}

\section{INTRODUCTION}

The importance of aerosol, and tropospheric aerosol in particular, on the atmospheric radiation budget and air quality is nowadays well recognized. The latest IPCC report states that the main cause of the uncertainty of the current estimation of aerosol direct and indirect effects on climate is the high variability in time and space of the distribution and microphysical properties of tropospheric aerosols [1]. The vertical distribution of aerosol is of particular importance because it is a combined signature of atmospheric transport patterns, residence time in the atmosphere, and the efficiency of the vertical exchange.

EARLINET (European Aerosol Research Lidar Network) [2,3] has been providing aerosol optical properties vertical profiles over Europe since May 2000. As a unique lidar network mainly based on Raman aerosol systems, EARLINET is the only "tool" able to provide a climatology of aerosol profiles. Here for the first time a long-term climatological study is performed using the quality assured database, in terms of AOD, free troposphere contribution to the AOD and intensive properties. The accuracy and representativeness of the measurements is addressed combining EARLINET with external datasets typically used as reference in literature such as AERONET and MODIS AOD data.

\section{METHODOLOGY}

The long-term aerosol observations collected within EARLINET allow a climatological study of aerosol properties over Europe. Here data published in the first volumes of EARLINET data 
were used [4-8]. EARLINET assures high quality products in terms of aerosol optical properties profiles thanks to quality assurance and quality check protocols. Every 2 years EARLINET quality checked data are published on the CERA database of the world data center for climate (WDCC) (www.dkrz.de/WDCC/). Data are freely available, as soon as stations PI finalize them, through EARLINET (www.earlinet.org) and ACTRIS data portal (actris.nilu.no). Additional datasets and products tailored for specific interests are moreover freely available on request.

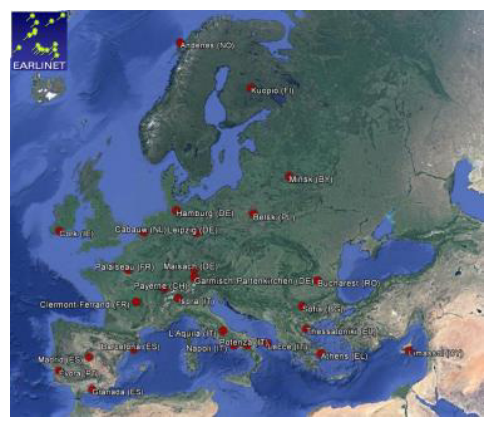

Figure1. Map of the EARLINET stations updated on June 2014.

In particular, only profiles related to measurements performed following the climatological schedule established within EARLINET were used for climatological purposes in order to avoid potential biases due to specific intensive measurements campaign related to events. The columnar AOD is calculated from each extinction profile of the EARLINET database, integrating the aerosol extinction profile over the whole column. In the AOD calculation from lidar measurements it has been taken into account that extinction values are not provided down to the ground because of the laser-telescope overlap region. For calculating the total column aerosol optical depth, it is considered that the aerosol extinction is constant in the lowest part of the atmosphere because of the well mixed conditions typically observed in the first nighttime hours.

From the extinction profile, it is also possible to provide an estimation of the free troposphere contribution (FT) to the total aerosol load. FT can be calculated in percentage to the total AOD starting from information provided by lidar about the PBL top [9] and the extinction profile directly measured by lidars.
As reference point and for representativeness considerations, AOD values provided by the closest Aerosol Robotic NETwork (AERONET) site and by MODIS (MODerate Resolution Imaging Spectroradiometer) at $1^{\circ} \times 1^{\circ}$ resolution were used. The Ångström exponent as measured by AERONET are used for scaling AOD with the wavelength when needed. In particular we used only quality assured AERONET data (namely Level 2 data) and MODIS collection 5 data. The temporal coincidence between EARLINET and AERONET/MODIS data cannot be obtained at a lower scale than 1 day, because the AOD EARLINET data are measured in nighttime conditions, while AERONET and MODIS measurements are possible only in daytime. Starting from these considerations, the comparison between the different datasets is carried out comparing EARLINET data to AERONET and MODIS daily average.

This permits, first of all, to measure directly the AOD, a key parameter for understanding the aerosol role on radiation budget. The comparison of EARLINET AOD measurements vs. MODIS and AERONET ones, allows on one hand to confirm the high quality of EARLINET data and on the other hand to investigate the representativeness of our network regular scheduling for climatological studies.

\section{RESULTS}

The comparison between EARLINET AOD and the corresponding values from AERONET collocated stations and MODIS $1^{\circ} \times 1^{\circ}$ confirms the reliability of EARLIENT columnar AOD, even under the assumption of well-mixed conditions below the first sounded point. In particular the one-to-one comparison with collocated AERONET data shows that, for all the stations, difference in AOD follows a Gaussian distribution centered around values in agreement with 0 within 1 std deviation (on average centered around 0.07). Differences are distributed according to a Gaussian distribution even for the MODIS comparison. The agreement in this case is also improved (center of the distribution on average is 0.02 ) probably because the larger horizontal area could smooth out the differences due instead to the non simultaneous measurements. 
Once the good reliability of EARLINET AOD columnar values is proved, the larger temporal coverage of both AERONET and MODIS can be used to understand if the regular schedule is sufficient for climatological purposes and at which extend. Temporal series of monthly, seasonal and annual averages resulting from the 3 datasets are compared in terms of root mean square (RMS) difference and correlation coefficient. Figure 2 and 3 report the RMS as a function of the correlation coefficient for EARLINET vs. AERONET and MODIS, repsectively. We also considered as interesting parameter the number of cases $\mathrm{N} / \mathrm{N}_{\text {tot }}$ for each time series for which the observed difference is within one standard deviation: i.e. cases for which $\mathrm{t}=\left|\mathrm{AOD}_{\text {ear }}-\mathrm{AOD}_{\text {aer }}\right| / \sigma_{\mathrm{AER}}$ is less than 1 .

In the AERONET comparison, it is clear that a pretty good agreement is found already for the monthly averages (small RMS and correlation above 0.4 and colors corresponding to $\mathrm{N} / \mathrm{N}_{\text {tot }}$ greater than $50 \%$ ). The seasonal average improves the situation moving points towards the bottom right corner and cold colors. Even negative correlations are recorded for annual averages because of too few simultaneous data between EARLINET and AERONET. The presence of negative correlation between time series when few points are compared, is observed also in the comparison with MODIS (Figure 3). Apart from this, a very good agreement is found for both seasonal and annual averages.

This analysis shows that the EARLINET climatological schedule, taking also into account that typically up to half of the scheduled measurements are performed because of weather and/or /man power limitations, is significant for climatological purposes if at least seasonal averages are considered and they could be representative also for $1^{\circ} \times 1^{\circ}$ for these time scales.

Consequently, the EARLINET dataset can be used to investigate continental and regional modification of aerosol properties over Europe. The last IPCC report [1] shows a general tendency of a reduction of the AOD over Europe, but little research has been done to date to identify the reason of it.

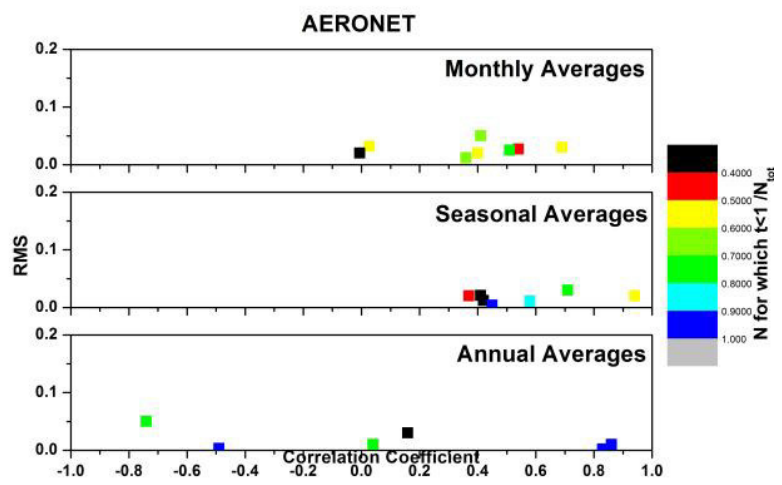

Figure 2: RMS as a function of correlation coefficient between EARLINET and AERONET time series of monthly, seasonal and annual averages (from top to bottom). Colors correspond to percentage of cases with observed differences in 1 std deviation.

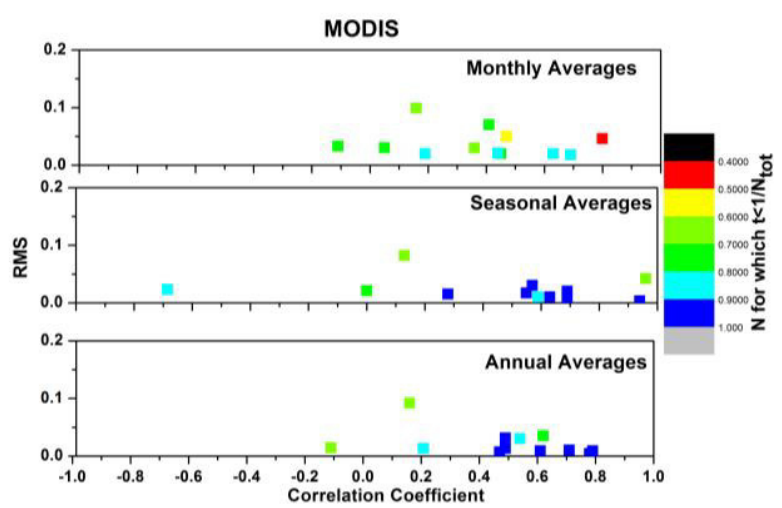

Figure 3: as Fig. 2 but for EARLINET vs. MODIS series.

The EARLINET measurements of course show this decrease. EARLINET observations add to this general framework another important point: in 2000-2010 a general tendency for decreasing of PBL contribution to the columnar AOD is observed (not shown). To understand this point, intensive properties as lidar ratio (S) at $355 \mathrm{~nm}$ and backscatter-related Angstrom exponent $(\delta)$ at $355 / 532 \mathrm{~nm}$ averaged in the PBL were investigated. The analysis was limited to these parameters because they are the ones with the largest number of available measurements. Figure 4 reports the time series of $S$ and $\delta$ for one station in the Mediterranean and one in Central Europe with the largest number of measurements at the present time (Potenza and Leipzig, respectively). 


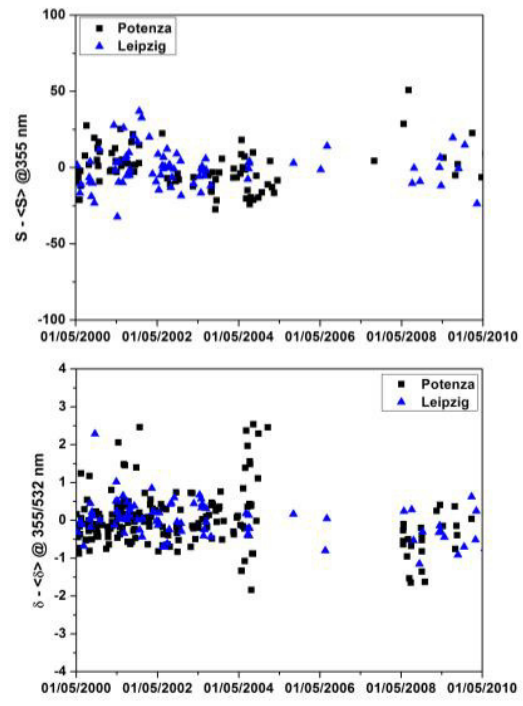

Figure 4. Temporal behavior of PBL mean values of lidar ratio at $355 \mathrm{~nm}$ (S) and backscatterrelated Ångström exponent at 355/532 $\mathrm{nm}(\delta)$ for Potenza and Leipzig stations. Data are normalized in respect to each site mean value.

Data are normalized respect to the specific site mean values for removing differences due to the specific location and emissions. It can be observed an increase in both $S$ and $\delta$ for the 2000-2002 period and a slight decrease afterwards. This would indicate a possible modifications towards less absorbing and slightly larger particles in the PBL over Europe.

\section{CONCLUSIONS}

A detailed study about the significance of EARLINET measurements has been carried out. The high quality dataset of aerosol optical properties vertical profiles has been compared with well recognized datasets of columnar measurements. This allowed a quantification of reliability of EARLINET columnar investigation. The efficiency of EARLINET climatological schedule for climatological purpose has been demonstrated. The representativeness on average of EARLINET punctual measurements at $1^{\circ} \times 1^{\circ}$ scale over seasonal /annual scale was proved.

EARLINET columnar observations in agreement with other platforms show a reduction of AOD over Europe. The EARLINET capability to investigate the vertical profiles shows that this reduction is due to the decrease of the PBL contribution to the total column AOD. Through investigation of aerosol intensive properties, we found that this could be ascribed to a modification of aerosol optical characteristics towards less absorbing and slightly larger particles. This could be related to the efficiency of pollution reduction actions over EU. Further investigations about vertical profiles and differences among the European regions could be carried out using the EARLINET database. In addition a combined study with near the surface measurements could add a further insight in this context.

\section{ACKNOWLEDGEMENT}

The financial support for EARLINET in the ACTRIS Research Infrastructure Project by the European Union under grant agreement n. 262254 in the $7^{\text {th }}$ Framework Programme (FP7/20072013) is gratefully acknowledged.

\section{REFERENCES}

[1] Boucher, O., et al., (2013), Fifth Assessment Report of the Intergovernmental Panel on Climate Change Cambridge University Press, Cambridge

[2] Bosenberg J. et al, (2001) in Advances in Laser Remote Sensing, 155-158.

[3] Pappalardo, G et al., (2014). Atmos. Meas. Tech., 7, 2389-2409

[4] The EARLINET publishing group 2000-2010, (2014)doi:10.1594/WDCC/EN_all_measurements _2000-2010.

[5] The EARLINET publishing group 2000-2010, (2014b)doi:10.1594/WDCC/EN_Climatology_20 00-2010.

[6] The EARLINET publishing group 2000-2010, (2014)doi:10.1594/WDCC/EN_Calipso_20062010.

[7] The EARLINET publishing group 2000-2010, (2014)doi:10.1594/WDCC/EN_VolcanicEruption _2000-2010.

[8] The EARLINET publishing group 2000-2010, (2014)doi:10.1594/WDCC/EARLINET_Saharan Dust_2000-2010.

[9] Matthias V. et al., (2014), J. Geophys. Res. 109. 